\title{
Energy balance of ice streams
}

\author{
C. F. RAYMOND \\ Geophysics Program, University of Washington, Box 351650, Seattle, Washington 98195-1650, U.S.A.
}

\begin{abstract}
Analysis of the cross-flow transmission of force from the central parts of a well-lubricated ice stream to its margins shows that there is a corresponding shift in the lateral location of motion-induced heat generation. The rate of basal heat generation in the center can be substantially smaller than the local rate of potential energy loss given by driving stress times the speed of downslope motion. The basal heating is a maximum for an intermediate level of lubrication for which speed is about $40 \%$ of the speed over a frictionless bed and base stress is about $25 \%$ of the driving stress. Stable and unstable balances between meltwater production and drainage on the bed are identified. A stable steady state with a speed less (more) than that giving maximum heat generation is termed drainage(production-) limited, since an increase in speed would lead to increased (decreased) basal melting and must (need not) be balanced by increased drainage. It is shown that gradual evolution of the basal water drainage system and the factors affecting basal melting can cause discontinuous jumps between fast- and slow-moving states. A simplified analysis applied to six cross-sections of West Antarctic Ice Streams B, D, E and Rutford Ice Stream shows them to be diverse in the level of support from the sides and corresponding shift of mechanical heating sideward from their central parts. The cross-sections of Ice Stream B near "Upstream B" may be production-limited, because of especially high lubrication and related support from the sides. Cross-sections in the upper part of Ice Stream D, Ice Stream $\mathrm{E}$ and Rutford Ice Stream are in a drainage-limited condition. Substantial reduction of basal heat generation by side drag (in most cases) and expected high heat flow into the basal ice associated with low thickness (in some cases) tends to favor basal freezing. Nevertheless, all of the examined cross-sections except one are expected to experience basal melting with a modest geothermal heat-flux density of $60 \mathrm{~mW} \mathrm{~m}^{-2}$ or less in some cases. The lower part of Ice Stream B is an exception, where the analysis indicates that geothermal flux density must exceed $80-100 \mathrm{~mW} \mathrm{~m}^{-2}$ to maintain melting. If this high geothermal flux is not present, then the base of the lower part of Ice Stream B may be freezing, which would suggest continued deceleration of this part of Ice Stream B.
\end{abstract}

\section{INTRODUGTION}

The ice streams of the Siple Coast of the West Antarctic ice sheet are bands of rapidly moving ice that play a crucial role in the discharge of ice to the ocean and the mass balance of the ice sheet (Alley and Whillans, 1991). The rapid streaming motion is enabled by lubrication of the base by pressurized water and weak subglacial till (Engelhardt and others, 1990), which allows the rapid motion in spite of very low surface slopes and associated gravitational driving stress.

Examination of the force balance (Van der Veen and Whillans, 1989) has revealed that Siple Coast ice streams are supported in part from their lateral margins (Echelmeyer and others, 1994; Scambos and others, 1994; MacAyeal and others, 1995; Jackson and Kamb, 1997; Whillans and Van der Veen, 1997; Harrison and others, 1998). A related implication is that some of the energy from downslope motion will be dissipated by shearing in the ice near the margins rather than at the ice base in the central part of the ice stream.

The partitioning of energy dissipation between the margins and the bed is important in view of the role played by basal meltwater in lubrication of the bed. It becomes especially significant given that the balance of heat conducted to the base of ice streams could be negative (Engelhardt and others, 1990). Net conduction of heat away from the bed would cause freezing and could operate to eliminate lubrication unless there were a compensating production of heat by the motion.

Raymond (1995) showed that maximum basal heat production and generation of meltwater occurs for an intermediate level of lubrication, and defined regimes in which the acceleration of an ice stream by accumulation of basal water is limited by increasing capacity of the drainage system or alternatively by declining water production.

This paper uses a theoretical model of margin drag to develop the basis for these concepts more fully. I explore the partitioning between bed and margins of the motiongenerated heat and examine the corresponding implications for the basal water balance that maintains lubrication in the central portion of an ice stream. Six cross-sections across Ice Streams B, D, E and Rutford Ice Stream are examined to identify characteristics for force balance and consequences for mechanical heating and associated melting on their beds.

\section{DESGRIPTION OF PROGESSES}

Figure 1 shows a schematic cross-section of an ice stream and adjacent ridges. The two important processes to quantify are motion over the base and deformation in the ice associated with lateral shearing across the margins. 
Motion over the base is described by a relationship between basal velocity $u_{\mathrm{b}}$ and shear stress $\tau_{\mathrm{b}}$ given by

$$
u_{\mathrm{b}}=\left(\frac{\tau_{\mathrm{b}}}{\tau_{0}}\right)^{m} \text {. }
$$

The parameter $m$ allows a power relationship between $u_{\mathrm{b}}$ and $\tau_{\mathrm{b}}$. The parameter $\tau_{0}$ represents resistance to slip (an inverse lubrication) determined by the physical state of the bed as affected by roughness, till thickness, overburden stress, water pressure, amount of water storage and/or possibly other variables.

Equation (1) can represent basal motion derived from a variety of physical assumptions including sliding of ice over a rough hard bed (Weertman, 1957) or deformation of soft, water-saturated basal till (Alley, 1989). Experimental investigations of till suggest a nearly cohesion-less, frictional-plastic behavior (Kamb, 1991; Iverson and others, 1998), which would be represented by $m \rightarrow \infty$. The base of an ice stream may be heterogeneous, possibly contacting rock or locked till as well as deforming, dilated till. The basal motion may therefore involve a combination of sliding, till deformation, and ice deformation around sticky spots (Alley, 1993; Echelmeyer and others, 1994; MacAyeal and others, 1995; Engelhardt and Kamb, 1997). Thus, the basis for choosing specific values for $\tau_{0}$ and $m$ in Equation (1) remains unclear. Equation (1) is adopted here because it allows the possibility that $u_{\mathrm{b}}$ increases monotonically with $\tau_{\mathrm{b}}$ for a fixed level of lubrication because of stress-dependent deformation in the ice around sticky spots or in the till.

The inverse lubrication $\tau_{0}$ is used as an adjustable input variable to determine the locations and speeds of nonstreaming and streaming flow. Outside of ice-stream boundaries, $\tau_{0}$ is taken to be effectively infinite, which suppresses slip. Under the ice streams, $\tau_{0}$ is taken to be small enough to predict significant $u_{\mathrm{b}}$ with low $\tau_{\mathrm{b}}$. The main purpose is to discover how the distribution of speed, stress and related energy dissipation is affected by the value of $\tau_{0}$ under an ice stream. Later it will be assumed that $\tau_{0}$ decreases monotonically with increasing water volume stored at the bed as described by an equivalent thickness $\delta$ (i.e. more water gives lower sliding resistance $\tau_{0}$ and higher lubrication $1 / \tau_{0}$ ).

The ice is assumed to deform in simple shear at strain rate $\dot{\epsilon}$ in response to shear stress $\tau$ according to power-law creep (Paterson, 1994, p. 97)

$$
\dot{\epsilon}=E A \tau^{n} \text {. }
$$

$\epsilon$ and $\tau$ are the shear strain-rate and stress magnitudes. $A$ and $n$ are the standard flow-law parameters. $A$ depends on temperature. $E$ is an enhancement factor for simple shear to account for ice fabric.

\section{FORGE AND ENERGY BALANGE}

As an ice stream becomes more lubricated at its base, one expects several related consequences for the dynamics: the force balance is shifted more strongly toward support from the margins; the shear stress at the base of the ice stream drops; the speed increases. These effects on basal stress and speed have implications for generation of heat at the base of the ice stream in its central parts. Rate of mechanical generation of heat per unit area $P$ is given by the product of basal velocity $u_{\mathrm{b}}$ and shear stress $\tau_{\mathrm{b}}$. Thus, it will be low for low lubrication, which causes $u_{\mathrm{b}}$ to be low. It will also be low for high lubrication, which causes $\tau_{\mathrm{b}}$ to be low. Clearly, there

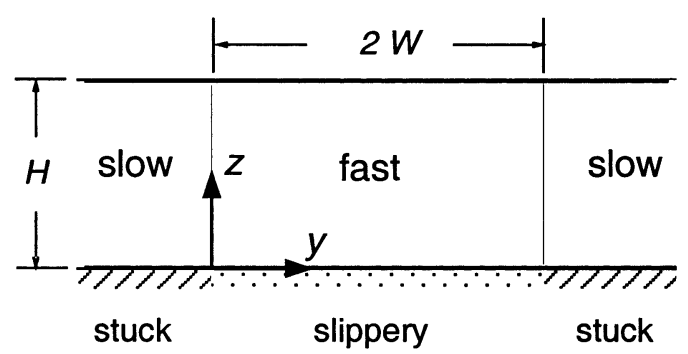

Fig. 1. Descriptive cross-section of an ice stream and definition of coordinate system.

will be a maximum at an intermediate level of lubrication (Raymond, 1995). I investigate the dependencies of $u_{\mathrm{b}}, \tau_{\mathrm{b}}$ and $P=u_{\mathrm{b}} \tau_{\mathrm{b}}$ on the amount of lubrication (related to $\tau_{0}$ in Equation (1)) using methods in Raymond (1996), henceforth referred to as R96.

To determine $u_{\mathrm{b}}$ and $\tau_{\mathrm{b}}$ in the center of an ice stream, I use the basal-motion (Equation (1)) and ice-flow (Equation (2) ) laws coupled through force balance in the direction of ice-stream motion $(x)$ as given by

$$
\frac{\partial \tau_{x x}}{\partial x}+\frac{\partial \tau_{x y}}{\partial y}+\frac{\partial \tau_{x z}}{\partial z}-\frac{\partial p}{\partial x}+\rho g \alpha=0
$$

where $\tau_{i j}$ are components of deviatoric stress, $p$ is mean compressive stress, $\rho$ is ice density, $g$ is gravitational acceleration, and $\alpha$ is the surface slope in the direction of icestream motion.

Of primary interest is stress and velocity on the bed in the ice stream, so I integrate Equations (3), (1) and (2) from the margin $(y=0)$ inward into the ice stream to the center $(y=W)$ along the base $(z=0)$. The coupled equations are simplified by accounting for primary characteristics of the flow expressed by the following assumptions:

(1) Thickness $H$, slope $\alpha$ and lubrication $\left(1 / \tau_{0}\right)$ are all independent of horizontal position in the ice stream, and width does not vary along the length. Longitudinal gradients are not central to the problem addressed here. In reality they may be large locally because of topography or variations of $\tau_{0}$ on the bed, but on average they are generally small compared to the transverse gradients (Bindschadler and Scambos, 1991; Whillans and Van der Veen, 1993). In some cases the across-flow transition from sheet to streaming flow may be gradual (e.g. Scambos and others, 1994). However, the primary characteristic is a sharpjump in lubrication beneath the margin as evidenced by the strong concentration of shear in the margins (Echelmeyer and others, 1994), and this can be captured with $\tau_{0}$ constant under the ice stream.

(2) Along-flow longitudinal $(x)$ gradients in both deviatoric stress $\tau_{x x}$ and pressure $p$ are negligible, so that

$$
\partial \tau_{x x} / \partial x=\partial p / \partial x=0
$$

This follows from assumption (1).

(3) Lateral $(y)$ gradients dominate vertical $(z)$ gradients $(\partial u / \partial y \gg \partial u / \partial z)$, so that

$$
2 \dot{\epsilon} \approx|\partial u / \partial y| \quad \tau \approx\left|\tau_{x y}\right|
$$

This assumption becomes valid over most of the width of an ice stream at high levels of lubrication appropriate for fast-moving ice streams (R96). 
(4) Vertical shear stress gradient at the bed is equal to the average over the thickness, as described by

$$
\partial \tau_{x z}\left(y, z_{\mathrm{b}}\right) / \partial z=-\tau_{\mathrm{b}} / H
$$

This assumption is consistent with the commonly assumed linear variation of shear stress with depth (Paterson, 1994, p. 251).

Introduction of these assumptions into Equations (3), (1) and (2) gives the ordinary differential equation involving only the $y$ variation of $u_{\mathrm{b}}$ along the bed $z=0$,

$$
\frac{\mathrm{d}}{\mathrm{d} y}\left[\frac{1}{2 E A} \frac{\mathrm{d} u_{\mathrm{b}}}{\mathrm{d} y}\right]^{\frac{1}{n}}-\frac{\tau_{0}}{H} u_{\mathrm{b}}^{\frac{1}{m}}+\rho g \alpha=0,
$$

where I use $\mathrm{d} u_{\mathrm{b}} / \mathrm{d} y>0$ for $y$ directed inward toward the ice-stream center. The function $u_{\mathrm{b}}(y)$ can be found by solving Equation (7) over $y=[0, W]$ with boundary conditions $u_{\mathrm{b}}(0)=0$ and $\mathrm{d} u_{\mathrm{b}}(W) / \mathrm{d} y=0$, where $y=0$ is the margin and $y=W$ is the center (Fig. 1). The function $\tau_{\mathrm{b}}(y)$ can then be calculated from Equation (1). Since the primary concern here is with conditions near the center line $y=W$, I focus on $u_{\mathrm{b}}(W)$ and $\tau_{\mathrm{b}}(W)$, which will henceforth be denoted simply as $u_{\mathrm{b}}$ and $\tau_{\mathrm{b}}$.

R96 (figs 7 and 8) showed that results from this approximate one-dimensional model of Equations (1-3) along the base are consistent with two-dimensional finite-element calculation of flow in the cross-section that fully includes both the lateral and vertical gradients in the force balance (Equation (3)) as long as the basal motion in the center is much larger than the speed produced by shearing through the thickness. This condition is appropriate for active ice streams moving over well-lubricated beds. While assumptions 3 and 4 may break down locally near the margin or center, those failures do not strongly affect the calculated shape of $u_{\mathrm{b}}(y)$ or more importantly $u_{\mathrm{b}}(W)$ derived from the integration from the margin to the center, which is of interest here.

It is useful to consider solution to Equation (7) for the limiting cases of no drag from the margins (low lubrication) and no friction on the bed (perfect lubrication). Straightforward solutions exist for both cases.

Low lubrication corresponds to no lateral gradients $(\mathrm{d} / \mathrm{d} y=0)$, and solution of Equation (7) for $u_{\mathrm{b}}$ gives

$$
U_{\mathrm{b}} \equiv u_{\mathrm{b}}=\left(\frac{T}{\tau_{0}}\right)^{m}
$$

where

$$
T \equiv \rho g \alpha H
$$

is the driving stress. $T$ is the value that $\tau_{\mathrm{b}}$ would have at the base of a sloped, planar ice slab with thickness $H$, slope $\alpha$ and no gradients parallel to the surface (Paterson, 1994, p.239, 240). $U_{\mathrm{b}}$ is the basal speed that $\tau_{\mathrm{b}}=T$ would produce with the basal motion law (Equation (1)). It is an alternative measure of how well the bed is lubricated.

Solution of Equation (7) for perfect lubrication (completely frictionless bed $\tau_{0}=0$ ) with constant $A$ and $E$ (Nye, 1952) gives speed in the center $y=W$ as

$$
U^{*}=\frac{2 \overline{E A}}{n+1}(\rho g \alpha)^{n} W^{n+1}=U_{\mathrm{d}} w^{n+1},
$$

where

$$
w \equiv \frac{W}{H}
$$

is the thickness-scaled half-width and

$$
U_{\mathrm{d}} \equiv \frac{2 \overline{E A}}{(n+1)} T^{n} H \text {. }
$$

I will refer to $U^{*}$ as the frictionless speed. Here $U_{\mathrm{d}}$ represents specifically the frictionless speed in the center of a hypothetical ice stream of half-width $W=H(w=1$ in Equation (10)). It is an alternative measure of the deformability of the ice for lateral shearing. When the ice is anisotropic and/or temperature varies spatially, then $E A$ must be spatially averaged as indicated by $\overline{E A}$. The appropriate averaging of $E A$ for the transverse shearing of primary concern here is considered below. (If the ice were isotropic and isothermal, then $U_{\mathrm{d}}$ could also be interpreted as the velocity difference that would result from surface-parallel shearing through the vertical thickness of a slab of thickness $H$ acted on by a base stress $T$ (Paterson, 1994, p. 251).)

The quantities $T, U^{*}, U_{\mathrm{d}}$ and $U_{\mathrm{b}}$ will be useful as scales for stress and velocity for representing other solutions to Equation (7).

Other analytical solutions for Equation (7) are known for $n=1, m=1$ (R96, equation (36)) and $n=$ arbitrary, $m=\infty$ (e.g. R96, equation (39)). Solutions for other combinations of $n$ and $m$ can be found by numerical integration. The main numerical difficulty arises from the split boundary conditions and the singularity at $y=W$. These problems are most easily handled by integrating from $y=W_{1}$ toward the edge with $\mathrm{d} u_{\mathrm{b}}\left(W_{1}\right) / \mathrm{d} y$ negligibly small and an assigned positive $u_{\mathrm{b}}\left(W_{1}\right)$. The actual half-width $W$ is found as $W=$ $W_{1}-W_{2}$ where $u_{\mathrm{b}}\left(W_{2}\right)=0$ defines the location of the edge. Numerical exploration of the solutions for various $W$ and $\tau_{0}$ is facilitated by using a dimensionless form with the scaling for $u_{\mathrm{b}}$ and $y$ introduced in R96 (equations (4b), (5), (31), (34) and (35)).

I first compare results for a range of non-linearity in the basal motion law (Equation (1)) spanned by values for $m$ from 1 to $\infty$. For this purpose $\tau_{0}$ (or $1 / \tau_{0}$ ) is not an appropriate measure of lubrication, since the dimensions of $\tau_{0}$ depend on $m$. Quantities related to $u_{\mathrm{b}}$ (e.g. R96) do not work for $m=\infty$ for which $u_{\mathrm{b}}$ is undefined by Equation (1). It is convenient to use $\tau_{\mathrm{b}}$ itself as a lubrication measure in the form $1-\tau_{\mathrm{b}} / T$, which goes from 0 (low lubrication with the bed supporting the full driving stress) to 1 (fully lubricated, frictionless bed). Figure 2 shows solutions for $u_{\mathrm{b}}, \tau_{\mathrm{b}}$ and $P$ vs this measure of lubrication for $n=3$ with $m=1, m=3$ and $m=\infty$. An essentially equivalent representation for the heat generation for the case $m=\infty$ has also been worked out by Tulaczyk and others (2000).

In all of these cases, speed increases and basal shear stress decreases with increasing lubrication. A maximum in heat generation occurs at intermediate lubrication, as expected on a qualitative basis. The quantitative predictions are not strongly dependent on $m$ in the basal motion law (Equation (1)).

Table 1 lists the maximum $P$ and the associated $u_{\mathrm{b}}$ and basal $\tau_{\mathrm{b}}$ that give the maximum as shown by comparison of Figure 2c with Figure 2a and b. I include results for $n=1$ (ice assumed to be a linear fluid) for completeness, but below I consider only $n=3$, which is more applicable to ice in the stress range of interest for marginal shearing. The maximum $P$ occurs at a basal shear stress $\tau_{\mathrm{b}}$ about $25-30 \%$ of the driving stress $T$, i.e. with a lubrication with somewhat more drag from the margins than the base. The speed at the maximum $P$ is about $40 \%$ of the frictionless speed $U^{*}$ (Equation $(10)$ ). 


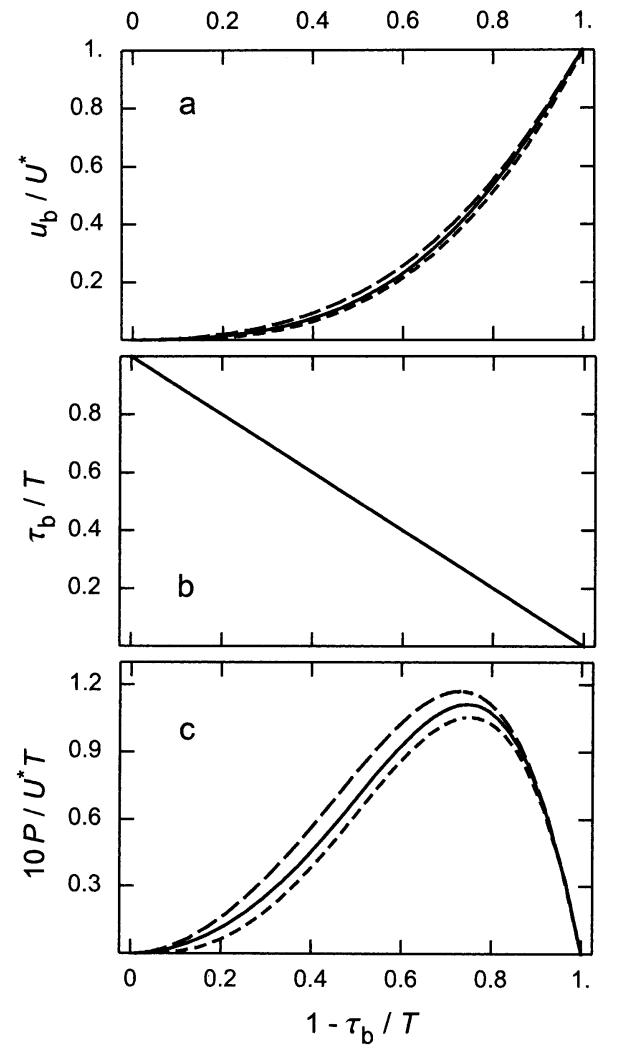

Fig. 2. Velocity $u_{\mathrm{b}}$ scaled by frictionless velocity $U^{*}(a)$, basal shear stress $\tau_{\mathrm{b}}$ scaled by driving stress $T(b)$ and heat production per unit area $P$ scaled by $T U^{*}(c)$ in the center of an ice stream as a function of fractional reduction in $\tau_{\mathrm{b}}$ relative to $T$. Curves show results for $n=3$ with $m=1$ (dashed), $m=3$ (solid) and $m=\infty$ (short dashed). (Note the scaling of the vertical axis in (c) by a factor of 10.)

The maximum $P$ is about $10 \%$ of the frictionless rate of potential energy loss $U^{*} T$. These results show that dynamic feedback considerably diminishes dissipation of potential energy loss locally on the bed in the center of the stream.

To consider the implications of the general pattern displayed by Figure 2, I focus primarily on the case $n=3, m=$ 3. Figure 3 shows the solution for $n=3, m=3$ with bed lubrication represented by the dimensionless quantity $U_{\mathrm{b}} / U^{*}$.

I choose to explore $m=3$, because 3 is intermediate in the potential range of $m[1, \infty]$. Furthermore, if basal till is much weaker than $\tau_{\mathrm{b}}$, then the resistance to basal motion comes from bed roughness or strong "sticky" spots, and this resistance is probably accommodated by ice deformation that would tend to impose $m=n$.

For $m=3$ (or more generally for $m \neq \infty$ ), I choose to represent bed lubrication by the dimensionless quantity $U_{\mathrm{b}} / U^{*}$ for several reasons. Equations (8) and (10) show that

$$
\frac{U_{\mathrm{b}}}{U^{*}}=\left(\frac{2}{E A} \frac{H^{3}}{\tau_{0}^{3} W^{4}}\right),
$$

so it depends only on input variables about geometry $(H, W$, $\alpha$ ), ice-flow law $(A, E, n=3)$ and slip law $\left(\tau_{0}, m=3\right)$. It has the advantage over $\tau_{\mathrm{b}}$ used in Figure 2 that it does not depend on the solution itself. It has the advantage over $\tau_{0}$ that it is dimensionless and accounts for the geometry of the ice stream. By reference to the limiting low- and perfectlubrication cases described above, $U_{\mathrm{b}} / U^{*}=1$ represents the transition from relatively low $\left(U_{\mathrm{b}} / U^{*} \ll 1\right)$ to relatively high $\left(U_{\mathrm{b}} / U^{*} \gg 1\right)$ lubrication.

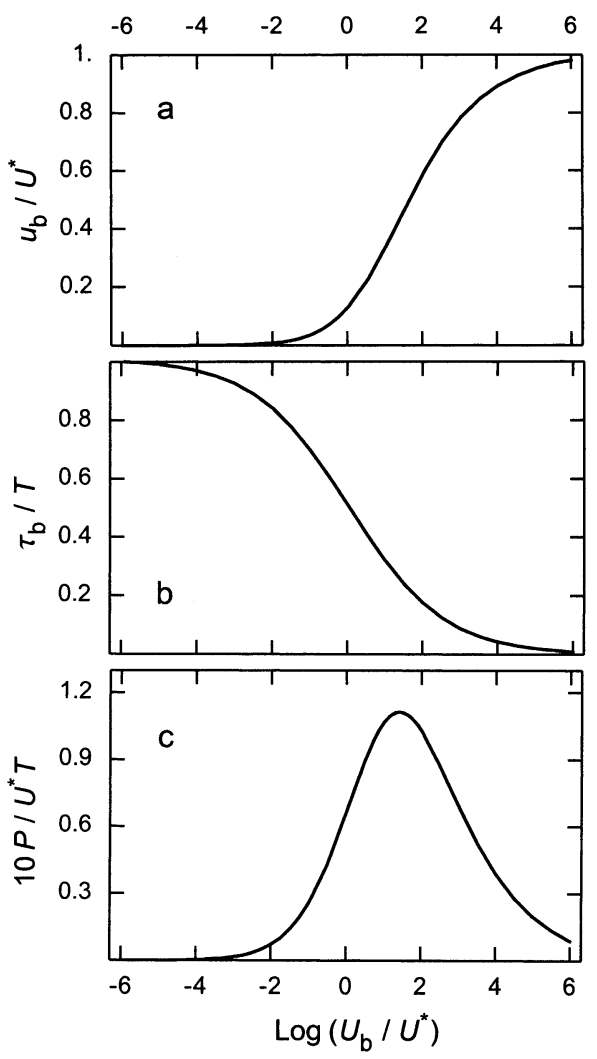

Fig. 3. Velocity $u_{\mathrm{b}}$ scaled by frictionless velocity $U^{*}(a)$, basal shear stress $\tau_{\mathrm{b}}$ scaled by driving stress $T(b)$ and heat production per unit area $P$ scaled by $T U^{*}(c)$ in the center of an ice stream as a function of width-scaled lubrication measured as $U_{\mathrm{b}} / U^{*}$ for $n=3, m=3$.

Figure $3 \mathrm{a}-\mathrm{c}$ define functions that give $u_{\mathrm{b}} / U^{*}, \tau_{\mathrm{b}} / T$ and $P / U^{*} T$ in terms of the input variables that define $U_{\mathrm{b}} / U^{*}$ (Equation (13)). Of particular interest below is the function relating $P$ to $\tau_{0}$. With the above definitions and evaluation of $T$ and $U^{*}$ using Equations (9) and (10), $P$ can be described as

$$
P=U^{*} T \mathcal{P}\left(\frac{U_{\mathrm{b}}}{U^{*}}\right)=\frac{A}{2}(\rho g \alpha W)^{4} H \mathcal{P}\left(\frac{2}{E A} \frac{H^{3}}{\tau_{0}^{3} W^{4}}\right),
$$

where $\mathcal{P}$ is the function $P / U^{*} T=\mathcal{P}\left(U_{\mathrm{b}} / U^{*}\right)$ plotted in Figure 3c.

\section{DRAINAGE/MELT INTERACTION}

The amount of water stored per unit area at the bed is here denoted by the thickness $\delta$. It will be increased by melting $m$ and decreased by flow divergence associated with the drainage system denoted by $d$. Water balance is given by

$$
\dot{\delta}=m(\delta)-d(\delta),
$$

where both $m$ and $d$ are allowed to depend on $\delta$. I assume

\begin{tabular}{|c|c|c|c|c|c|}
\hline$n$ & 1 & 3 & 3 & 3 & $n$ \\
\hline$m$ & 1 & 1 & 3 & $\infty$ & $\infty$ \\
\hline$P_{\max } /\left(U^{*} T\right)$ & 0.29 & 0.115 & 0.113 & 0.105 & $n^{n} /(n+1)^{n+1}$ \\
\hline$\left.\left(u_{\mathrm{b}} / U^{*}\right)\right|_{\max }$ & 0.51 & 0.39 & 0.45 & 0.42 & {$[n /(n+1)]^{n}$} \\
\hline$\left.\left(\tau_{\mathrm{b}} / T\right)\right|_{\max }$ & 0.57 & 0.29 & 0.25 & 0.25 & $1 /(n+1)$ \\
\hline
\end{tabular}

Table 1. Maximum basal heating rate and associated speed and stress 


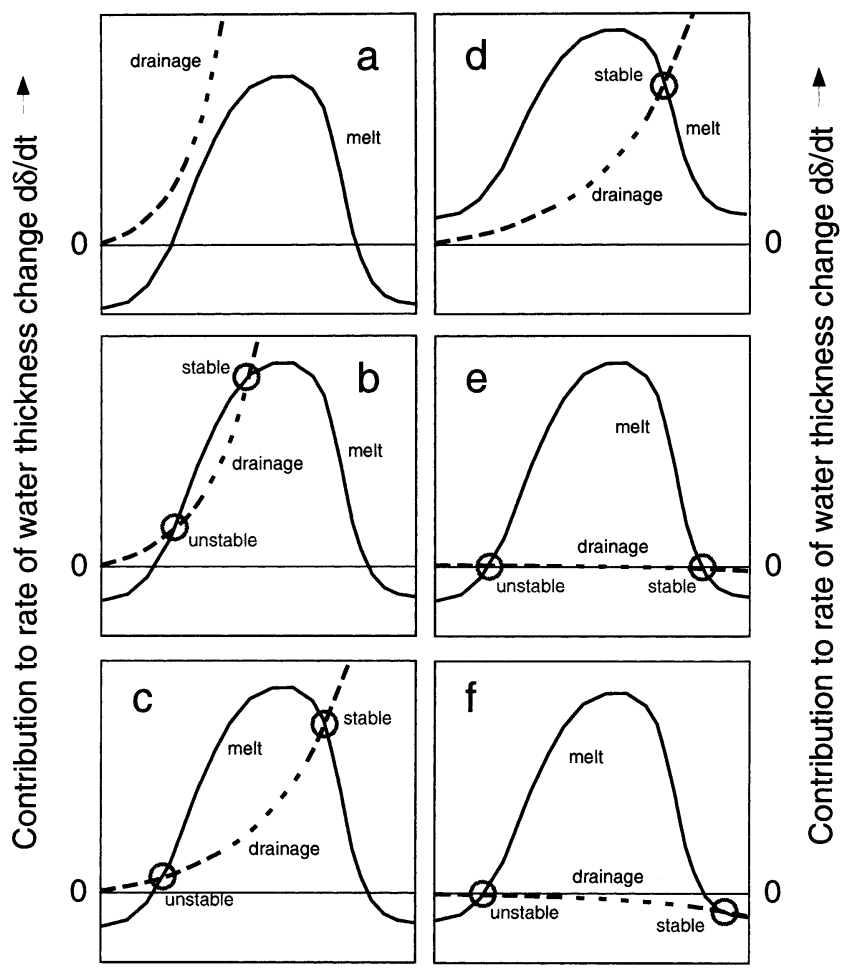

Effective water thickness $\delta \rightarrow$

Fig. 4. Schematic comparison of rates of meltwater production (solid curve) and drainage (dashed curve) depending on basal water storage $\delta$ in six alternative scenarios discussed in the text. It is assumed that heat conduction removes heat from the bed at rate $(Q-G>0)$, so that melting is turned off where $P<Q-G$ (Equation (16)) as at low and high $\delta$ in $(a-c, e, f)$. In $(d)$, it is assumed that $Q-G<0$, so that there is melting $(m>0)$ even when $P \Rightarrow 0$.

that the same water influences $m$ and $d$, and $\delta$ is the thickness of that water. This assumption is not necessarily correct. However, it is a reasonable starting-point for a representative location on the bed outside of through-going passageways.

The basal melting rate can be represented by

$$
m=(P-Q+G) / \rho_{\mathrm{w}} L .
$$

$P$ is the mechanically generated heating rate per unit area (section 3, e.g. Equation (14)). $Q$ is the heat-flux density conducted upward into the ice away from the ice base. $G$ is the geothermal heat-flux density conducted upward from the rock to the base. $Q-G$ is the net conductive heat loss. $P-Q+G$ is then the total power per unit area that melts water thickness depending on the latent heat per unit mass $L$ and the density of liquid water $\rho_{\mathrm{w}}$.

Melting rate $m$ depends on $\delta$ through $P$ (Equation (16)). I assume that there is a monotonically decreasing relationship $\tau_{0}(\delta)$ (i.e. more water gives lower sliding resistance $\tau_{0}$ and higher lubrication $\left.1 / \tau_{0}\right)$. Introduction of $\tau_{0}(\delta)$ into Equation (14) gives $P(\delta)$. Since $\tau_{0}(\delta)$ is assumed to be monotonic, $P(\delta)$ will have the same qualitative character as the dependence of $P$ on lubrication found in section 3 (i.e. maximum at an intermediate $\delta$ ) as shown in Figures 2 and 3. The corresponding pattern $m=m(\delta)$ defined from Equation (16) is shown schematically in Figure 4 as solid curves. Although $P$ is always positive, $m$ can be negative, which occurs at low and high lubrication (now represented by $\delta$ ) when there is net conductive heat loss $(Q-G>0)$.
I will assume that the drainage $d(\delta)$ is a monotonically increasing function of water thickness $\delta$, since larger $\delta$ would tend to facilitate water transfer. Schematic representation of $d(\delta)$ is shown in Figure 4 as dashed curves. Such a relationship is reasonable as long as the sinks for locally generated meltwater (e.g. relatively low-pressure canals (Walder and Fowler, 1994) or other drainage passages) do not become more widely spaced, more highly pressurized or completely destroyed as $\delta$ increases (e.g. Kamb, 1987).

A quantitative development of the evolution of $\delta(t)$ requires specification of $\tau_{0}(\delta)$ and $d(\delta)$ (e.g. Kamb, 1991), but the knowledge to quantify these relationships is still limited. In addition, the evolution of fields of temperature (affecting $Q$ and $G$ ), hydraulic potential on the bed (affecting $d(\delta))$ and ice thickness (affecting all of the processes) must be tracked for a complete development. I will stick to the relatively secure qualitative features of the meltwater production and drainage as described above. I also assume that distributions of temperature, hydraulic potential and ice thickness are slowly evolving in comparison to rates of change in $\delta$ as driven by the dependencies of $P$ and $d$ on $\delta$. With these limitations in mind, several possible qualitative joint relationships between $m(\delta)$ and $d(\delta)$ are illustrated schematically in Figure 4 . The alternative scenarios illustrate potential ways in which $\delta(t)$ could evolve.

Where $m(\delta)>d(\delta), \delta$ increases (water builds up). That would allow acceleration of the ice stream. The opposite effect would follow from $m(\delta)<d(\delta)$. A steady state requires $m\left(\delta_{0}\right)=d\left(\delta_{0}\right)$, i.e. an intersection of the solid and dashed curves in Figure 4 at a particular water thickness $\delta_{0}$. A steady state defined by $m\left(\delta_{0}\right)=d\left(\delta_{0}\right)$ may be stable or unstable, for example as found by Kamb (1991).

The stability of a steady state at water thickness $\delta_{0}$ can be examined based on the change in water-balance rate $\dot{\delta}$ caused by a small shift of $\delta$ from $\delta_{0}$. To first order in $\delta-\delta_{0}$, $\dot{\delta}=\left[m^{\prime}\left(\delta_{0}\right)-d^{\prime}\left(\delta_{0}\right)\right]\left(\delta-\delta_{0}\right)$. An intersection such that $m$ increases less rapidly than $d$ as $\delta$ rises $\left(m^{\prime}\left(\delta_{0}\right)-d^{\prime}\left(\delta_{0}\right)<0\right)$ would be stable (e.g. as labeled in Fig. 4$)$. In that case, an incremental increase in $\delta$ from the steady state $\left(\delta_{0}\right)$ would result in a negative water-balance rate that would return $\delta$ toward $\delta_{0}$. An incremental decrease in $\delta$ would similarly return toward $\delta_{0}$. On the other hand, an intersection such that $m$ increases more rapidly than $d$ as $\delta$ rises $\left(m^{\prime}\left(\delta_{0}\right)-d^{\prime}\left(\delta_{0}\right)>0\right)$ would be unstable (e.g. as labeled in Fig. 4).

If $m(\delta)<d(\delta)$ for all $\delta$ (Fig. 4a), there is no steady lubricated state, stable or unstable. Water drains away and lubrication cannot be sustained. Otherwise, there will be one stable steady state (all other panels) and possible associated unstable steady states (Fig. 4b, c, e and f).

The stable steady state is of primary interest. Two qualitative conceptual alternatives may be distinguished (Raymond, 1995): a "drainage-limited" regime, for which the stable steady state occurs at a lubrication less than produces maximum $m$ (Fig. 4b); and a "production-limited" regime, for which it occurs at lubrication larger than produces the maximum $m$ (Fig. $4 \mathrm{c}-\mathrm{f}$ ). In the drainage-limited regime, an increase in drainage $d$ with increase in water thickness $\delta$ is required to prevent runaway of the ice-stream speed from the stable steady state. No such increase in $d$ is required in the production-limited regime, where a drop in melt rate $m$ can stabilize the speed by itself.

Except for Figure 4d, all panels in Figure 4 are drawn as if conduction removes heat from the bed $(Q>G)$. A consequence is that melting cannot be sustained at very low or high $\delta$ where $P$ is insufficient to balance $Q-G$ and $m<0$ 
(Equation (16)). If there were no drainage at all as suggested by Tulaczyk and others (2000), then the unstable and stable steady states would be as in Figure 4e. To maintain a very high speed approaching frictionless speed $U^{*}$, as in Figure $4 \mathrm{f}$, would require import of water $(d<0$, negative drainage) to balance freeze-on $(m<0)$. Although water import would certainly be a necessary condition, the question remains whether such import is possible or sufficient to maintain lubrication and fast motion (Tulaczyk and others, 2000). A condition of positive conductive heat balance $(Q<G)$ would require positive drainage independent of $P$ (Fig. $4 \mathrm{~d}$ ); however, the same discussion concerning drainage- and production-limited regimes still holds unchanged.

Now suppose that there is evolution of ice-stream conditions along its length because of adjustment to climate or internally driven time-dependent processes. Such changes could affect drainage (e.g. pressure distribution or spacing of water sinks), the basal heat generation (e.g. stress and velocity driven by slope and thickness) and conductive heat balance at the bed (e.g. geothermal heat in response to temperature history of the ice base). The two-dimensional modeling in a cross-section considered here cannot predict such evolution. We can, however, consider the local response in a cross-section with the supposition that these processes shift the drainage and/or melt production curves (Fig. 4).

For an active ice stream the dynamic feedback from the margins allows a smooth response with the stable steady state migrating to higher or lower speed (e.g. Fig. 4b and c). There are some important differences in how drainage- and production-limited steady states could respond. A drainagelimited steady state will have higher sensitivity to equivalent shifts because of the narrow angle of intersection of the curves for $d$ and $m$ (Fig. 4). Clearly, a drainage-limited condition has much more potential for large increases in speed. In a production-limited steady state, increase in speed tends to be self-limiting because of reduction in meltwater production, and the ultimate upper limit of frictionless speed is not so distant.

A potential for large jumps in speed is also evident. If the drainage curve separates from the melt-production curve (Fig. 4a), there would be a jump to no lubrication and nearly stagnant condition with negligible heat generation similar to an inter-ice-stream location. An ice stream could be restarted from low speed only in situations with a positive conductive heat balance at the bed (Fig. 4d) or with water import from an upstream source (Fig. 4f). Either of these circumstances could lead to a jump to a high-speed steady state. These concepts illustrate the potential for jump-like transitions between stagnant and active phases with self-propagating and large changes in velocity once thresholds have been reached.

\section{EXAMPLE WEST ANTARGTIC ICE STREAMS}

A crucial question is, what limits the speed of active ice streams? I examine whether those active West Antarctic ice streams with sufficient observations appear to be drainageor production-limited as defined above. To facilitate comparison of different ice-stream cross-sections in the context of force and energy balance for the center of each ice-stream cross-section, I construct a dynamic-feedback diagram (Fig. 5) showing contours of $\tau_{\mathrm{b}} / T$ and $P / U_{\mathrm{d}} T=u_{\mathrm{b}} \tau_{\mathrm{b}} / U_{\mathrm{d}} T$ with $w=W / H$ and $u_{\mathrm{b}} / U_{\mathrm{d}}$ as coordinates.

Figure 5 is constructed by using the functional relation-

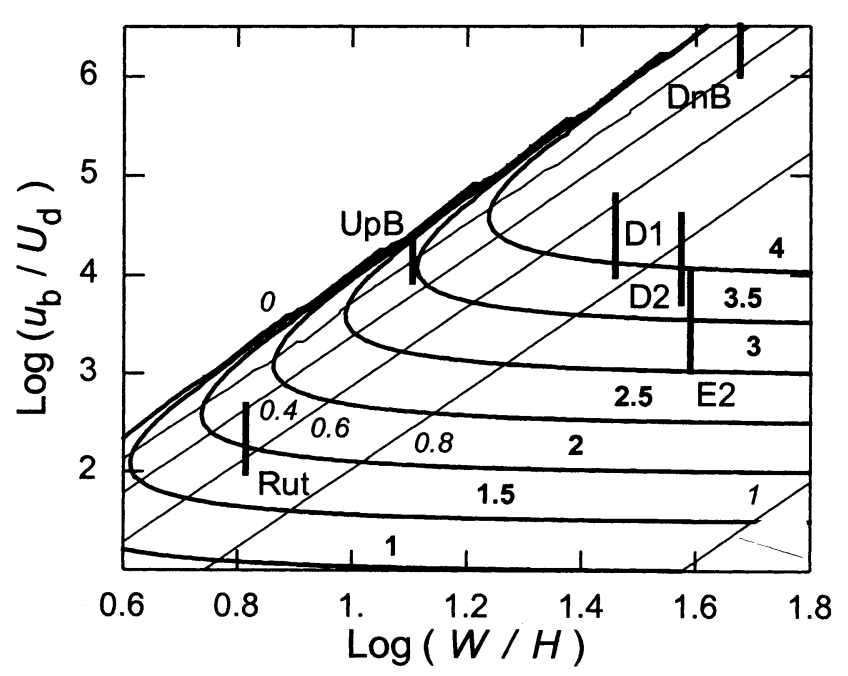

Fig. 5. Contours of heat production rate $P$ (heavy curves) and basal shear stress $\tau_{\mathrm{b}}$ (light lines) in the center of an ice stream for varying width $W$ and speed $u_{\mathrm{b}}$. Labels for contours of $P$ (boldface numbers) give log base 10 values of $P$ in units of $U_{\mathrm{d}} T$. Labels of contours for $\tau_{\mathrm{b}}$ (italic numbers) give $\tau_{\mathrm{b}} / T$. Note also the scaling of axis variables $W$ and $u_{\mathrm{b}}$. The diagonal line $\tau_{\mathrm{b}} / T=0$ gives the speed for a frictionless bed $U^{*}=U_{\mathrm{d}} w^{4}$. States above this line are not accessible. Similarly, states below the line $\tau_{\mathrm{b}} / T=1$ are not accessible.

ships in Figure 3 (or Fig. 2 for $n=3, m=3$ ) and eliminating explicit reference to a measure of lubrication $\left(\tau_{\mathrm{b}}, U_{\mathrm{b}}, \tau_{0}\right.$ or $\left.\delta\right)$. The limits of $u_{\mathrm{b}}$ lie between $U_{\mathrm{d}}$ (low lubrication, bed drag regime) and $U^{*}=U_{\mathrm{d}} w^{4}$ (perfect lubrication with frictionless velocity, side drag regime). The plot is restricted to $u_{\mathrm{b}} / U_{\mathrm{d}}>$ 10 , for which the simplified one-dimensional theory for lateral variations in section 3 is valid. For this range it is also reasonable to ignore the distinction between $U_{\mathrm{d}}$ as a scale for lateral shearing and shearing over the ice thickness that arises when the ice is non-isothermal and/or anisotropic (Equations (10) and (12)). For a fixed $w$ in Figure 5, the contour patterns for $\tau_{\mathrm{b}}$ and $P$ represent the curves in Figure 3 with low $\tau_{\mathrm{b}}$ at high $u_{\mathrm{b}}$ and low $P$ at both low and high $u_{\mathrm{b}}$ with a maximum in between.

This strategy for examining the relationship amongst the four variables $W, u_{\mathrm{b}}, \tau_{\mathrm{b}}$ and $P=u_{\mathrm{b}} \tau_{\mathrm{b}}$ is convenient for comparing measurements because $W, H$ and $u_{\mathrm{b}} \approx u_{\mathrm{s}}$ are the most accessible variables for observation. $U_{\mathrm{d}}$ (Equation (12)) can be estimated from $H$ and $\alpha$ with information about the distributions of temperature and enhancement $E$ and the associated flow law of ice (Equation (2)). The dimensionless formulation of Figure 5 allows plotting of any cross-section based on the values of $u_{\mathrm{b}} / U_{\mathrm{d}}$ and $W / H$. Then $\tau_{\mathrm{b}} / T$ and $P / U_{\mathrm{d}} T$ can be read off from their respective contour patterns (keeping in mind possible error in $U_{\mathrm{d}}$, which causes uncertainty in the vertical position of the plotted point). Similarly $T$ can be estimated from $H$ and $\alpha$, so that dimensional values for $\tau_{\mathrm{b}}$ and $P$ can be determined (subject to errors in $T$ and also $U_{\mathrm{d}}$ in the case of $P$ ).

Table 2 (rows 1-6) gives basic input data to analyze five sections across ice streams of the Siple Coast and a characteristic one for Rutford Ice Stream. Sources for the data are given in the table. The names in Ice Stream B follow common usage (UpB and DwnB). In Ice Streams D and E, the definitions in Bindschadler and others (1996) are used (D1, D2 and E2). (Note that Scambos and others (1994) used D5 to denote D2.) The section in Rutford Ice Stream is based on representative data from sections adjacent to the upstream 
part of Fletcher Promontory (Frolich and Doake, 1988). The primary data are thickness $H$, half-width $W$, surface slope $\alpha$ and surface velocity $u_{\mathrm{s}}$ (rows $1-4$ ). In these ice streams the surface $u_{\mathrm{s}}$ and bed $u_{\mathrm{b}}$ velocities are essentially the same. The surface temperature $\theta$ and accumulation rate $a$ (rows 5 and 6) are also of interest for estimating the temperature distribution relevant to the flow law (Equation (2)).

Thickness-scaled half-width $w$ is found from full width $2 W$ and thickness $H$ (Equation (11); Table 2, row 7). Although full width $2 W$ is known fairly accurately, there is some ambiguity in specifying the half-width $W . W$ is defined by boundary conditions in the analysis above to be the distance from the margin to the flow center line, where $\partial u / \partial y=0$. This location may not be halfway between the two margins because of asymmetry in cross-flow thickness and bed conditions. I take $W$ to be half the full width. This choice should give an average picture for the two margins of the crosssection, although it may not represent either one accurately.

It is straightforward to calculate the driving stress $T$ (Equation (9); Table 2, row 8) from thickness $H$ and surface slope $\alpha$. The primary uncertainty for $T$ comes from $\alpha$.

The vertical distribution of temperature was estimated following Robin (1955) using the recent surface temperature $\theta$ (Table 2 , row 5 ), accumulation rate $a$ (Table 2 , row 6 ) and a basal heat-flux density into the ice $Q$ adjusted to give melting temperature at the base (Table 2, row 9). This vertical temperature distribution was assumed to apply independent of lateral position.

The calculation of $U_{\mathrm{d}}$ (Equation (12); Table 2, row 10) is complicated by poorly known spatial variation of temperature and fabric affecting the flow law (Equation (2)). The spatial pattern of $A(T)$ was estimated from a standard temperature-dependent representation of the flow law (Paterson, 1994, p. 97) and the Robin temperature distribution. The following approach was used to estimate a limiting range for $U_{\mathrm{d}}$ arising from uncertainty in enhancement. First, an effective
$E A$ was determined by vertically averaging $A(T)$ and $E=1$. The vertical average of $A$ produced by this method corresponds to $A$ evaluated at a temperature of about $-9^{\circ} \mathrm{C}$, which is warmer than the vertically averaged temperature of about $-16^{\circ} \mathrm{C}$. Second, effective $E A$ was estimated as above but including an enhancement $E=10$ at the margin with a fall-off to $E=1$ over about $30 \%$ of the half-width $W$. This spatial pattern of enhancement is similar to that estimated in the margin of Ice Stream B2 by Echelmeyer and others (1994). These two assumptions for enhancement $(E=1$ everywhere and $E=10$ in the margin zone) span from relatively small (Jackson and Kamb, 1997; Whillans and Van der Veen, 1997; Harrison and others, 1998) to substantial (Echelmeyer and others, 1994), arising from estimates of side drag at Upstream $\mathrm{B}(\mathrm{UpB})$ using a variety of measurements. The effect on $U_{\mathrm{d}}$ is a factor of about 3. Additional uncertainty in $U_{\mathrm{d}}$ arises from uncertainty in $T$, which extends the potential range of $U_{\mathrm{d}}$ typically by another factor of 2 or more.

With $H, W, \alpha, u_{\mathrm{b}}, U_{\mathrm{d}}$ and $T$ in hand for a given crosssection as discussed above, it can be plotted in Figure 5, and derived quantities $\tau_{\mathrm{b}} / T \Rightarrow \tau_{\mathrm{b}}$ (Table 2 , rows 14 and 15) and $P / T U_{\mathrm{d}} \Rightarrow P$ (Table 2 , rows 12 and 16 ) can be read from the figure.

This simple analysis for force balance (Fig. 5; Table 2, row 14) gives the following results. For cross-sections in Ice Streams B (UpB and DwnB), $\tau_{\mathrm{b}} / T \leq 0.5$, so they are supported strongly from the sides. In all of the other crosssections, $\tau_{\mathrm{b}} / T \geq 0.5$, and they are not so strongly supported from the sides. However, side support is by no means negligible in any of the cross-sections. The results of this simple analysis are roughly consistent with other, more thorough, evaluations of force balance using more extensive data and analysis including attempts to account for enhancement $(E>1)$ and variable bed conditions (Frolich and Doake, 1988; Echelmeyer and others, 1994; Scambos and others, 1994; Jackson and Kamb, 1997; Whillans and Van der Veen,

Table 2. Active ice-stream characteristics

\begin{tabular}{|c|c|c|c|c|c|c|c|}
\hline & & $U_{p} B$ & $D w n B$ & $D 1$ & $D 2$ & $E 2$ & Rut \\
\hline \multicolumn{8}{|c|}{ Observation } \\
\hline 1 & $H(\mathrm{~km})$ & 1.1 & 0.8 & 0.9 & 0.9 & 1.1 & 2 \\
\hline 2 & $W(\mathrm{~km})$ & 14 & 38 & 23 & 30 & 38 & 12 \\
\hline 3 & $\alpha\left(10^{-3}\right)$ & 1.3 & 0.4 & {$[1.3,1.7]$} & {$[1.3,1.8]$} & {$[1.6,2.3]$} & 2.3 \\
\hline 4 & $u_{\mathrm{b}}\left(\mathrm{km} \mathrm{a}^{-1}\right)$ & 0.43 & 0.51 & 0.63 & 0.4 & 0.4 & 0.38 \\
\hline 5 & $\theta\left({ }^{\circ} \mathrm{C}\right)$ & -26 & -26 & -26 & -26 & -26 & -26 \\
\hline 6 & $a\left(\mathrm{~m} \mathrm{a}^{-1}\right)$ & 0.1 & 0.1 & 0.1 & 0.1 & 0.1 & 0.3 \\
\hline \multicolumn{8}{|c|}{ Scales } \\
\hline 7 & $w$ & 13 & 48 & 26 & 33 & 35 & 6 \\
\hline 8 & $T(\mathrm{kPa})$ & 13 & 2.8 & {$[10,13]$} & {$[10,14]$} & {$[16,23]$} & 41 \\
\hline 9 & $Q\left(\mathrm{~mW} \mathrm{~m}^{-2}\right)$ & 81 & 101 & 92 & 92 & 81 & 95 \\
\hline 10 & $U_{\mathrm{d}}\left(\mathrm{mm} \mathrm{a}^{-1}\right)$ & {$[20,50]$} & {$[0.1,0.5]$} & {$[10,64]$} & {$[10,76]$} & {$[38,400]$} & {$[600,3900]$} \\
\hline 11 & $U^{*}\left(\mathrm{~km} \mathrm{a}^{-1}\right)$ & {$[0.5,2.0]$} & {$[0.9,2.6]$} & {$[4,27]$} & {$[12,94]$} & {$[55,570]$} & {$[1,5]$} \\
\hline 12 & $T U_{\mathrm{d}}\left(\mu \mathrm{W} \mathrm{m}^{-2}\right)$ & {$[8,23]$} & {$[0.01,0.05]$} & {$[3,28]$} & {$[3,35]$} & {$[19,300]$} & {$[800,5000]$} \\
\hline 13 & $T U^{*}\left(\mathrm{~W} \mathrm{~m}^{-2}\right)$ & {$[0.2,0.6]$} & {$[0.1,0.2]$} & {$[1,11]$} & {$[4,43]$} & {$[27,424]$} & {$[1,6.5]$} \\
\hline \multicolumn{8}{|c|}{ Derived } \\
\hline 14 & $\tau_{\mathrm{b}} / T$ & {$[0,0.32]$} & {$[0.1,0.42]$} & {$[0.56,0.76]$} & {$[0.77,0.84]$} & {$[0.82,0.88]$} & {$[0.30,0.60]$} \\
\hline 15 & $\tau_{\mathrm{b}}(\mathrm{kPa})$ & {$[0,4]$} & {$[0.1,1.2]$} & {$[6,10]$} & {$[8,12]$} & {$[12,21]$} & {$[12,24]$} \\
\hline 16 & $P=\tau_{\mathrm{b}} u_{\mathrm{b}}\left(\mathrm{mW} \mathrm{m}^{-2}\right)$ & {$[0,55]$} & {$[2,19]$} & {$[120,210]$} & {$[101,150]$} & {$[174,280]$} & {$[140,300]$} \\
\hline 17 & $G_{\min }\left(\mathrm{mW} \mathrm{m}^{-2}\right)$ & {$[81,23]$} & {$[101,82]$} & none & none & none & none \\
\hline
\end{tabular}

Notes: Sources of observational information:

UpB (Upstream B): Echelmeyer and others (1994, analytical); Jackson and Kamb (1997); Whillans and Van der Veen (1997); Harrison and others (1998). DwnB (Downstream B): Bindschadler and others (1987); Whillans and Van der Veen (1997).

D1 and D2 (Ice Stream D): Scambos and others (1994); Bindschadler and others (1996).

E2 (Ice Stream E): MacAyeal (1992); MacAyeal and others (1995); Bindschadler and others (1996).

Rut (Rutford Ice Stream): Frolich and Doake (1988). 
1997; Harrison and others, 1998), with the exception of section E2 (MacAyeal and others, 1995) which is discussed further below.

The immediate consequence for heat generation on the bed is that $P=\tau_{\mathrm{b}} u_{\mathrm{b}}$ is less than $T u_{\mathrm{b}}$ as would be estimated without accounting for the force balance. Conditions in all of the analyzed cross-sections except D2 and E2 appear to be such that heat generation could be close to the maximum possible for their widths $W$. It would be very convenient if ice streams adjusted their speeds to achieve maximum $P$ and corresponding melt rate $m$. Then the speed would be about $40 \%$ of the frictionless speed $U^{*}$ (Table 1; Table 2, row 11; Fig. 5), and could be easily calculated from the geometry $(\alpha, H, W)$ and ice flow law $(A, E, n)$ (Equations (12) and $(10))$ without reference to the water drainage system. However, in the context of the discussion in section 4, there is no clear physical basis for maintaining a state of maximum heat production. That condition could lead to accumulation of basal water, increasing lubrication and acceleration of the ice stream (Fig. 4c or d) or the opposite (Fig. 4b) depending on the efficiency of the drainage system.

A production-limited regime is characterized by a speed that is larger than produces maximum heat generation. The upper range of scaled velocity estimated for Ice Stream B indicates the possibility that it is in a production-limited regime (Fig. 5). This would certainly be the case if side drag is very close to $100 \%$ as suggested by some of the examinations at Upstream B (Jackson and Kamb, 1997; Whillans and Van der Veen, 1997; Harrison and others, 1998). No drainage would be very convenient for modeling ice-stream motion (Tulaczyk and others, 2000). A no-drainage state would be a special case of a production-limited regime. In view of the uncertainties, this is a possible condition for Ice Stream B.

A drainage-limited regime is characterized by a speed that is smaller than produces maximum heat generation. Even with the substantial range of uncertainty, all of D1, D2, E2 and Rutford are evidently in a drainage-limited regime (Fig. 5). Drainage must play a crucial role in regulating these ice streams.

The predicted rate of mechanical generation of heat for each case in Figure 5 can be computed in dimensional form $P$ (Table 2, row 16) by introducing the unit $U_{\mathrm{d}} T$ (Table 2, row 12). There is a wide range. Under Ice Stream $B, P$ appears to be less than the likely geothermal heat flux $G\left(60 \mathrm{~mW} \mathrm{~m}^{-2}\right.$ or larger). Under D1 and D2, Rutford and E2, $P$ is distinctly larger than expectable $G$.

Comparison of $P$ with the upward flow of heat into the ice (denoted $Q$, Table 2, row 9 ), estimated by the thermal analysis described above, predicts the minimum geothermal heat $G_{\min }$ required to maintain melting at the ice base (Table 2, row 17). For this comparison it is important to keep in mind that the actual temperature distribution in the ice at any specific location will be influenced by along-flow advection of heat and non-steady conditions that are not taken into account by the Robin (1955) analysis. Therefore, there is considerable uncertainty in the estimated value of $Q$. Nevertheless, where it can be checked (at UpB) there is agreement between this prediction $\left(Q=81 \mathrm{~mW} \mathrm{~m}^{-2}\right)$ and measurement ( $Q=0.08 \mathrm{~W} \mathrm{~m}^{-2}$ found by Engelhardt and others, 1990).

For D1, D2, E2 and Rutford, $P>Q$, and no geothermal heat is needed. This holds even though $Q$ is predicted to be relatively high in D1 and D2, which are relatively thin, and Rutford, which has high accumulation rate. The important factor is that $P$ is high in these sections. Basal melting is ex- pected in all of them. At DnB $G$ needed to maintain melting is estimated to be large $\left(80-100 \mathrm{~mW} \mathrm{~m}^{-2}\right)$, because of a combination of low $P$ (associated with large side drag and production-limited regime) and high $Q$ (associated with low thickness). Normal $G$ would be distinctly smaller than this value, but higher values cannot be entirely ruled out in view of the history of rifting and low crustal thickness (Elliot, 1985). If the geothermal flux is near normal (about $60 \mathrm{~mW} \mathrm{~m}^{-2}$ ), the fast motion at DnB would then appear to be maintained even in the presence of basal freezing. The speed at $\mathrm{DnB}$ is presently decelerating (Bindschadler and Vornberger, 1998), and perhaps basal freezing is a contributing factor.

Section E2 in Ice Stream E deserves special discussion. In this analysis the basal shear stress $\tau_{\mathrm{b}}$ predicted at E2 is about $80-90 \%$ of the driving stress $T$ (Table 2, row 14). The substantial $\tau_{\mathrm{b}}$ compared to other cross-sections follows from relatively large $T$ and $W$, but nevertheless similar $u_{\mathrm{b}}$ (Table 2, rows 2, 3, 8 and 4). This result is distinctly different from conclusions in the rigorous inverse-theory analysis of the spatial pattern of velocity on Ice Stream E of MacAyeal and others (1995) in an area that encloses E2. The preferred interpretation of these authors is a mean $\tau_{\mathrm{b}}$ of $14 \mathrm{kPa}$ that is only $29 \%$ of a mean $T$ of $49 \mathrm{kPa}$. They suggest an upper limit for the fraction of support from the base of about $60 \%$. While there is reasonable agreement about the size of $\tau_{\mathrm{b}}, T$ and the fraction of support from the sides appear to be distinctly different in the two analyses. MacAyeal and others (1995) include large-scale horizontal support both laterally from the sides and longitudinally along the length without distinguishing between them. My analysis accounts only for lateral gradients, not longitudinal ones. Considering the range of uncertainty given in each analysis and the neglect of longitudinal stress gradients in mine, the two analyses could be reconciled with as little as $20 \%$ longitudinal support, which is a very reasonable possibility. On the other hand, reconciliation of the two analyses with the preferred interpretation of MacAyeal and others (1995) requires about $50-60 \%$ longitudinal support. It would be surprising if longitudinal gradients supported such a large proportion of $T$, since they are not larger than lateral gradients in the area of the cross-section E2 based on data in MacAyeal and others (1995) and Bindschadler and others (1996). The disagreement on the size of $T$ would presumably derive mainly from a difference in assumed surface slope $\alpha$ (here taken to be in the range $1.6-2.3 \times 10^{-3}$ based on the recent digital elevation model of Liu and others (1999)). However, introducing a larger surface slope in my analysis increases the disparity in the fraction of support from the bed. While it appears that the results from the two analyses can be reconciled by considering the outer limits estimated in each case and reasonable longitudinal gradients, the differences are disquieting. Neither D. MacAyeal (personal communication, 1999) nor I have a firm resolution. It is an important question that does point to the difficulties for assessing side and bed drag.

This discussion promotes caution in applying a generic model of cross-section flow that does not account for details of the lateral variations of thickness and velocity or longitudinal gradients to interpret specific cross-sections with many actual complexities. However, I have attempted to account for these problems using a reasonable range of variables to show that the general pattern of comparison between the different ice-stream sections is robust. It is clear that the icestream dynamics with respect to drainage-regulated lubrication and feedback from side drag are diverse. At a minimum 
level we can divide the sections investigated here into two groups: [B] and [D, E, Rutford].

The cause of the differences is of considerable interest with regard to the potential for large changes in discharge from the West Antarctic ice sheet. Ice Stream B is largely supported from its sides, and the potential for increase in speed by altering conditions at its base is limited. If the lubrication of the beds of Ice Streams D and/or E could be increased, the consequent increase in speed could be very large with positive feedback of increased basal melting. Are Ice Streams D and $\mathrm{E}$ different from Ice Stream B because the bed geology and/or morphology are different in a way that prevents a high level of lubrication? This would suggest stability of their discharges. Or are Ice Streams D and E in a different stage of evolution such that bed conditions could become like those at Ice Stream B? This would suggest possible instability of their discharges.

\section{GLOBAL ENERGY BALANGE}

Thus far, I have been concerned with force balance and consequences for generation of basal heat in the central parts of an ice stream. Although heat generation falls off in the center of an ice stream as speed increases in the high-speed, production-limited regime, the rate of total potential energy loss continues to increase toward the frictionless potential energy loss $U^{*} T$, which can be very large (Table 2, row 13). This energy is deposited toward the margins rather than in the center of the ice stream.

The lateral variation of mechanical energy dissipation and associated heating per unit area can be estimated analytically using the solution for a plastic bed $(m=\infty)$ (e.g. R96, equation (39)). Figure 6 shows the partitioning between the center and very edge of such a model ice stream derived in this simplified way. The estimate includes heating at the bed and through the ice column by side shearing. As the bed becomes more lubricated, an enormous amount of energy can be focused into the margins. This energy redistribution leads to shear heating as observed in the margin of Ice Stream B (Harrison and others, 1998). The vertical distribution of the heating in the ice and its effect on the temperature pattern may be complex (Jacobson and Raymond, 1998). Therefore, it is not straightforward to estimate what proportion of the heat is exhausted to the atmosphere and what causes melting. This question is not taken up here. Nevertheless, there is a theoretical potential for melting at the bed in and even beyond the margin (Jacobson and Raymond, 1998). This opens the possibility that the margins may play an important role in setting the paths of water drainage in ice streams.

\section{CONGLUSION}

The cross-flow transmission of force from an ice stream to its margins causes the heat generation on the bed in the center of a well-lubricated ice stream to be substantially smaller than would be deduced from the driving stress and measured speed. The production of meltwater for maintaining the lubrication is correspondingly less. The rate of basal heat generation is a maximum for an intermediate level of lubrication for which velocity is about $40 \%$ of the speed associated with a frictionless bed and base stress is about $25 \%$ of the driving stress. The maximum rate of heat generation

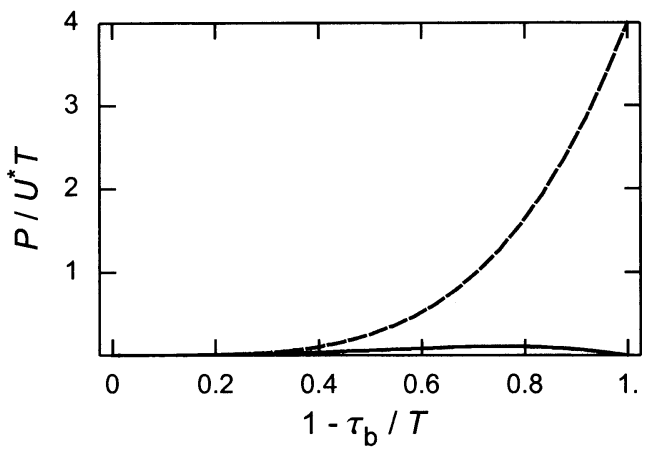

Fig. 6. Comparison of heat generation rate per unit area of bed at margin (dashed line) and center (solid line) derived assuming a laterally constant basal shear stress $\left(m=\infty\right.$ and $\tau_{0}=$ constant in Equation (1)). The value of $P$ is integrated over full thickness and includes shearing in the ice as well as generation at the bed.

is only about $10 \%$ of the rate given by the driving stress times the velocity over a frictionless bed.

Steady-state lubrication is achieved with equality of meltwater production and drainage. Both stable and unstable balances between meltwater production and drainage on the bed are possible. A stable steady state with a speed less (more) than that giving maximum heat generation is termed drainage- (production-) limited, since an increase in speed would lead to increased (decreased) basal melting and must (need not) be balanced by increased drainage. It is shown that a gradual continuous augmentation of the basal water drainage system or decline in basal melting can cause a discontinuous jump from a fast-moving steady state to a slow, stagnant state associated with a threshold in the balance between drainage and melting.

The redistribution of heat is particularly important with regard to the thermal control of ice streams. These effects arising from horizontal stress gradients across the flow are large (approaching 100\%) compared to effects on the conductive heat balance from varying thickness associated with surface and bed topography. Evidently, thermomechanical modeling of an ice sheet with ice streams must include the horizontal redistribution of stress and in particular the associated heating to capture thermal regulation of ice-stream expansion, contraction and shutdown.

Available information about the geometry and speed for six cross-sections from Ice Streams B, D, E and Rutford Ice Stream shows them to be diverse in the level of support and corresponding shift of mechanical heating sideward from their central parts. Ice Streams D and E and Rutford Ice Stream appear to be in a drainage-limited condition, where acceleration of speed would increase mechanical heat dissipation on the bed and thereby increase melting. Ice Stream $\mathrm{B}$ could possibly be in a production-limited condition, where increase in speed would actually reduce basal melting rate. This possible condition for the upper part of Ice Stream B arises because the reduction in basal heat generation from side drag is especially significant there.

The conduction of heat upward into the ice is also expected to vary amongst the different ice streams, with the highest upward conduction in Ice Stream D and the lower part of Ice Stream B, which are relatively thin.

In examined sections of Ice Streams D and E and Rutford Ice Stream, the mechanical generation of heat at the bed is larger than conducted upward into the ice, so that no geothermal heat is required to maintain their bases at melting and 
produce meltwater. This condition is predicted even though basal heating is significantly reduced by side drag and/or the heat loss into the basal ice is large. On the other hand, in the lower part of Ice Stream B, the combination of side-draginduced reduction of mechanical heating at the bed and high upward conduction into the ice requires a very high geothermal heat (more than about $80-100 \mathrm{~mW} \mathrm{~m}^{-2}$ ) to maintain a thawed condition. The lower part of Ice Stream B is a likely location where the dynamic reduction of mechanical heating on the bed contributes to basal freezing, which could promote slowing of speed and ice discharge. Ice Streams D and especially $\mathrm{E}$ have relatively high driving stress and large width, and the simplified analysis here identifying relatively low level of side drag suggests a potential for large increases in ice speed and discharge by enhanced lubrication of the bed. An already large rate of basal melting suggests that it may be difficult to develop lubrication with meltwater, possibly because the morphology of the bed is different than under Ice Stream B.

\section{ACKNOWLEDGEMENTS}

This research was supported by U.S. National Science Foundation grant Nos. OPP-9316807 and OPP-9725882. Comments from R. Hindmarsh and an anonymous reviewer helped improve the clarity and accuracy of this paper.

\section{REFERENGES}

Alley, R. B. 1989. Water-pressure coupling of sliding and bed deformation: II. Velocity-depth profiles. F. Glaciol., 35(119), 119-129.

Alley, R. B. 1993. In search of ice-stream sticky spots. F. Glaciol., 39(133), 447-454.

Alley, R. B. and I. M. Whillans. 1991. Changes in the West Antarctic ice sheet. Science, 254(5034), 959-963.

Bindschadler, R. A. and T. A. Scambos. 1991. Satellite-image-derived velocity field of an Antarctic ice stream. Science, 252(5003), 242-246.

Bindschadler, R. and P. Vornberger. 1998. Changes in the West Antarctic ice sheet since 1963 from declassified satellite photography. Science, 279(5351), 689-692.

Bindschadler, R. A., S. N. Stephenson, D. R. MacAyeal and S. Shabtaie. 1987. Ice dynamics at the mouth of Ice Stream B, Antarctica. F. Geophys. Res., 92(B9), 8885-8894.

Bindschadler, R., P. Vornberger, D. Blankenship, T. Scambos and R. Jacobel. 1996. Surface velocity and mass balance of Ice Streams D and E, West Antarctica. 7. Glaciol., 42(142), 461-475.

Echelmeyer, K.A., W. D. Harrison, C. Larsen and J. E. Mitchell. 1994. The role of the margins in the dynamics of an active ice stream. F. Glaciol., 40(136), 527-538.
Elliot, D. H. 1985. Physical geography, geological evolution. In Key environments - Antartica. New York, Pergamon Press, 39-61.

Engelhardt, H. and B. Kamb. 1997. Basal hydraulic system of aWest Antarctic ice stream: constraints from borehole observations. 7. Glaciol., 43(144), 207-230.

Engelhardt, H., N. Humphrey, B. Kamb and M. Fahnestock. 1990. Physical conditions at the base of a fast moving Antarctic ice stream. Science, 248(4951), 57-59.

Frolich, R. M. and C. S. M. Doake. 1988. Relative importance of lateral and vertical shear on Rutford Ice Stream, Antarctica. Ann. Glaciol., 11, 19-22.

Harrison, W. D., K. A. Echelmeyer and C. F. Larsen. 1998. Measurement of temperature in a margin of Ice Stream B, Antarctica: implications for margin migration and lateral drag. F. Glaciol., 44(148), 615-624.

Iverson, N. R., T. S. Hooyer and R. W. Baker. 1998. Ring-shear studies of till deformation: Coulomb-plastic behavior and distributed strain in glacier beds. f. Glaciol., 44(148), 634-642.

Jackson, M. and B. Kamb. 1997. The marginal shear stress of Ice Stream B, West Antarctica. 7. Glaciol., 43(145), 415-426.

Jacobson, H. P. and C. F. Raymond. 1998. Thermal effects on the location of ice stream margins. F. Geophys. Res., 103 (B6), 12,111-12,122.

Kamb, B. 1987. Glacier surge mechanism based on linked cavity configuration of the basal water conduit system. F. Geophys. Res., 92(B9), 9083-9100.

Kamb, B. 1991. Rheological nonlinearity and flow instability in the deforming bed mechanism of ice stream motion. F. Geophys. Res., 96(B10), 16,585-16,595.

Liu, H., K. C. Jezek and B. Li. 1999. Development of an Antarctic digital elevation model by integrating cartographic and remotely sensed data: a geographic information system based approach. 7. Geophys. Res., $104(\mathrm{~B} 10), 23,199-23,213$.

MacAyeal, D. R. 1992. The basal stress distribution of Ice Stream E, Antarctica, inferred by control methods. 7. Geophys. Res., 97(B1), 595-603.

MacAyeal, D. R., R. A. Bindschadler and T. A. Scambos. 1995. Basal friction of Ice Stream E, West Antarctica. F. Glaciol., 41(138), 247-262.

Nye, J. F. 1952. The mechanics of glacier flow. F. Glaciol., 2(12), 82-93.

Paterson, W. S. B. 1994. The physics of glaciers. Third edition. Oxford, etc., Elsevier.

Raymond, C. F. 1995. Constraints on the velocity of ice streams imposed by their widths. [Abstract.] EOS, 76(46), Fall Meeting Supplement, F208-F209.

Raymond, G. 1996. Shear margins in glaciers and ice sheets. f. Glaciol., 42(140), 90-102.

Robin, G. de Q. 1955. Ice movement and temperature distribution in glaciers and ice sheets. F. Glaciol., 2(18), 523-532.

Scambos, T. A., K. A. Echelmeyer, M. A. Fahnestock and R. A. Bindschadler. 1994. Development of enhanced ice flow at the southern margin of Ice Stream D, Antarctica. Ann. Glaciol., 20, 313-318.

Tulaczyk, S. M., B. Kamb and H. F. Engelhardt. 2000. Basal mechanics of Ice Stream B, West Antarctica. II. Undrained-plastic-bed model. F. Geophys. Res., 105(B1), 483-494.

Van der Veen, C. J. and I. M. Whillans. 1989. Force budget: I. Theory and numerical methods. F. Glaciol., 35(119), 53-60.

Walder, J. S. and A. Fowler. 1994. Channelized subglacial drainage over a deformable bed. F. Glaciol., 40(134), 3-15.

Weertman, J. 1957. On the sliding of glaciers. F. Glaciol., 3(21), 33-38.

Whillans, I. M. and C. J. van der Veen. 1993. Patterns of calculated basal drag on Ice Streams B and C, Antarctica. F. Glaciol., 39(133), 437-446.

Whillans, I. M. and C. J. van der Veen. 1997. The role of lateral drag in the dynamics of Ice Stream B, Antarctica. 7. Glaciol., 43(144), 231-237. 